\title{
EFEITO DO ÁCIDO GIBERÉLICO, DO BIOESTIMULANTE CROP SET E DO ANELAMENTO NA PRODUÇÃO E NA QUALIDADE DA UVA 'THOMPSON SEEDLESS' NO VALE DO SÃO FRANCISCO ${ }^{1}$
}

\author{
PATRÍCIA COELHO DE SOUZA LEÃO², DAVI JOSÉ SILVA², EMANUEL ÉLDER GOMES DA SILVA³
}

\begin{abstract}
RESUMO - O objetivo do presente trabalho foi avaliar os efeitos do ácido giberélico, do bioestimulante Crop Set e do anelamento sobre o aumento do tamanho de bagas e a produtividade da uva 'Thompson Seedless' no Vale do São Francisco. O experimento foi conduzido durante dois ciclos de produção (2001 e 2002), no Campo Experimental de Bebedouro, pertencente à Embrapa Semi-Árido, em Petrolina-PE. Utilizou-se do delineamento experimental de blocos ao acaso, com 12 tratamentos e 3 repetições. Os tratamentos corresponderam à aplicação de ácido giberélico em cinco fases de desenvolvimento da videira, nas doses de $10+15+15+50+50 \mathrm{mg} \cdot \mathrm{L}^{-1}$, do bioestimulante Crop Set em duas doses de 0,1 e $0,2 \%$ e do anelamento no caule, isolados e combinados entre si. Os tratamentos combinados de anelamento + ácido giberélico e anelamento + ácido giberélico + Crop Set destacaram-se como aqueles que promoveram os maiores peso e tamanho de cachos e de bagas, com diferenças significativas em relação à testemunha. Entretanto, o anelamento não cicatrizou completamente, causando a morte de plantas, recomendando-se cautela na sua realização. Apesar de não se observar efeito significativo dos tratamentos sobre a produtividade, pode-se notar um aumento de $63 \%$ para o tratamento anelamento + ácido giberélico em relação ao ciclo de produção de 2001.
\end{abstract}

Termos para indexação: Vitis vinifera, reguladores de crescimento, citocinina, uvas sem sementes.

\section{EFFECT OF GIBBERELLIC ACID, GIRDLING AND THE BIOSTIMULANT CROP SET ON YIELD AND QUALITY OF BUNCHES IN GRAPES CV. THOMPSON SEEDLESS IN THE SÃO FRANCISCO VALLEY}

\begin{abstract}
The present research was aimed to evaluate the effects of the gibberellic acid, the biostimulant Crop-Set and girdling applied during bloom and post-bloom stage to improve yield and berry size of the grape cv. Thompson Seedless in the São Francisco River Valley, Northeast of Brazil. The trial was carried out throughout two growing seasons (2001 and 2002) in the Bebedouro Experimental Station, Embrapa Semi-Árido, Petrolina, PE. The trial was laid out in a randomized complete block design with three replicates, each replicate consisting of a four-tree plot. The treatments were: gibberellic acid aplied during five phases of development $\left(10+15+15+50+50 \mathrm{mg} \cdot \mathrm{L}^{-1}\right.$ doses), Crop-Set in two doses 0,1 and $0,2 \%$ and trunk girdling, isolated or combined to each other. The combination treatments of girdling + gibberellic acid and girdling + gibberellic acid + Crop Set showed the best results, promoting the largest weight of bunches and size of berries with significative diferences compared to control. On the other hand, girdling caused damage in the tissue cicatrization and death of plants, so it is recomended caution to practice it. The yield was increased $63 \%$ in the combination girdling + gibberellic acid in the growing season of 2001, although it had not been observed significative diferences among treatments.
\end{abstract}

Index terms: Vitis vinifera, gibberelic acid, citokinin, girdling, seedless grape.

\section{INTRODUÇÃO}

A uva constitui uma das principais frutas exploradas no Vale do São Francisco, sendo a segunda fruta na pauta das exportações. Nos últimos anos, observou-se a expansão do cultivo de uvas sem sementes, sendo que a variedade Thompson Seedless tem despertado grande interesse, pois é a principal variedade de uvas sem semente cultivada no mundo e, portanto, com excelente aceitação no mercado externo.

Os cachos de 'Thompson Seedless' possuem bagas pequenas e cachos compactos, sendo necessária a realização de práticas para melhorar o aspecto dos cachos de acordo com os padrões comerciais.

As giberelinas destacam-se entre os reguladores de crescimento mais utilizados para a produção de uvas de mesa em todo o mundo, visando principalmente a aumentar o tamanho de bagas, a promover a descompactação dos cachos e a induzir a apirenia em uvas com sementes.

A utilização de ácido giberélico isolado ou associado ao anelamento na variedade Thompson Seedless é antiga, existindo inúmeras referências na literatura (Ezzahouani et al., 1985; Harrel \& Williams, 1987; Zioziou et al., 1999) que indicam a eficiência desses tratamentos para reduzir a compactação do cacho e aumentar o tamanho e o peso de bagas, podendo ocorrer ainda redução no teor de sólidos solúveis e atraso na maturação.

Dentre as hipóteses sobre o mecanismo mediante o qual as giberelinas podem estimular a expansão celular, destaca-se a da hidrólise do amido, resultante da produção da $\alpha$-amilase gerada pelas giberelinas, que pode incrementar a produção de açúcares, elevando a pressão osmótica no suco celular, de modo que a água entra no interior da célula e tende a expandi-la (Pires, 1998).

As citocininas são substâncias derivadas da purina adenina as quais causam divisão celular nas plantas, em geral por uma interação com auxinas. São produzidas nas raízes e transportadas até as folhas e redistribuídas para outros órgãos pelo xilema (Metiver, 1979). Extratos contendo citocininas foram obtidos de mais de 50 espécies, e os níveis mais altos são usualmente encontrados em tecidos nos quais está ocorrendo divisão celular (Metiver, 1979; Taiz \& Zeiger, 1991). O produto comercial Crop Set (Improcrop-Kentucky-USA) é um estimulante vegetal composto de extratos de agave (Yucca shidigera) e micronutrientes minerais com ação semelhante às citocininas. As pesquisas realizadas com a cultura da videira referem-se à utilização de citocininas sintéticas, como o CPPU (N-(2-chloro-4-pyridyl)-N'phenylurea), sendo obtidos resultados positivos sobre o aumento do tamanho e do peso de bagas quando combinado com o ácido giberélico (Navarro et al., 2001). Entretanto, existe forte tendência para preferência de produtos naturais que contenham citocinina.

O anelamento, por sua vez, promove acúmulo de carboidratos na parte da planta acima da incisão e é utilizado em uvas sem sementes para aumentar o tamanho de bagas, sobretudo como uma prática complementar à aplicação do ácido giberélico (Winkler, 1970).

O objetivo do presente trabalho foi avaliar a eficiência da aplicação do ácido giberélico, do anelamento e do bioestimulante Crop Set, isolados ou combinados entre si, sobre o aumento do tamanho de bagas e a produtividade da uva 'Thompson Seedless' no Vale do São Francisco.

\footnotetext{
${ }^{1}$ (Trabalho 190/2004). Recebido: 21/12/2004. Aceito para publicação: 05/10/2005.

${ }_{2}^{2}$ Pesquisadores Embrapa Semi-Árido, BR 428, Cx.Postal 23, Petrolina-PE, CEP.56.302-970, patricia@cpatsa.embrapa.br, davi@cpatsa.embrapa.br

${ }^{3}$ Eng. Agr. ${ }^{\circ}$, Fazenda Timbaúba Agrícola, BR 122, Km 174, Caixa Postal 123, Petrolina-PE, elder@timbaubagricola.com.br
} 
TABELA 1 - Efeitos do ácido giberélico (AG3), do anelamento e do bioestimulante Crop Set (CS) sobre cachos e bagas da uva 'Thompson Seedless', 2001, Petrolina-PE.

\begin{tabular}{|c|c|c|c|c|c|c|c|c|c|c|}
\hline TRATAMENTOS & $\begin{array}{c}\text { Peso médio } \\
\text { de cachos (g) }\end{array}$ & $\begin{array}{l}\text { Peso médio } \\
\text { de bagas (g) }\end{array}$ & $\begin{array}{r}\text { Comprimento } \\
\text { de bagas }(\mathrm{mm})\end{array}$ & $\begin{array}{l}\text { Diâmetro de } \\
\text { bagas (mm) }\end{array}$ & $\begin{array}{c}\text { Peso do } \\
\text { engaço (g) }\end{array}$ & $\begin{array}{l}\text { Produçã } \\
\text { o (t/ha) }\end{array}$ & $\begin{array}{c}\text { Cachos/ } \\
\text { planta }\end{array}$ & $\begin{array}{c}\text { SST } \\
\left({ }^{\circ} \text { Brix }\right)\end{array}$ & $\begin{array}{l}\text { ATT } \\
(\%)\end{array}$ & $\begin{array}{c}\text { Relação } \\
\text { SST/ATT }\end{array}$ \\
\hline $\mathrm{T}$ & $198,57 \mathrm{~b}$ & 1,87 & 16,70 & 13,86 & 7,65 & $6,20 \mathrm{a}$ & $50 \mathrm{a}$ & $21,23 \mathrm{a}$ & $0,74 \mathrm{a}$ & $28,80 \mathrm{a}$ \\
\hline A & $224,69 \mathrm{ab}$ & $2,64 \mathrm{de}$ & 19,06 & 15,30 & 7,96 & 5,86 a & $50 \mathrm{a}$ & $20,20 \mathrm{abc}$ & $0,77 \mathrm{a}$ & $26,03 \mathrm{ab}$ \\
\hline AG3 & $282,97 \mathrm{ab}$ & $3,21 \mathrm{~cd}$ & 22,83 & 15,36 & $12,20 \mathrm{abcd}$ & $10,64 \mathrm{a}$ & $46 \mathrm{a}$ & $19,70 \mathrm{bcd}$ & $0,78 \mathrm{a}$ & $25,43 \mathrm{ab}$ \\
\hline CS $0,1 \%$ & $242,50 \mathrm{ab}$ & $2,65 \mathrm{de}$ & 18,93 & 15,53 bcde & $9,10 \mathrm{~cd}$ & $6,97 \mathrm{a}$ & $45 \mathrm{a}$ & 20,06 abcd & $0,77 \mathrm{a}$ & $26,03 \mathrm{ab}$ \\
\hline $\operatorname{CS~} 0,2 \%$ & $238,97 \mathrm{ab}$ & $2,38 \mathrm{de}$ & 18,06 & 15,03 & 9,38 bcd & $6,78 \mathrm{a}$ & $44 \mathrm{a}$ & $20,36 \mathrm{ab}$ & 0,76 a & $26,90 \mathrm{ab}$ \\
\hline $\mathrm{A}+\mathrm{CS} 0,1 \%$ & $282,04 \mathrm{ab}$ & $2,79 \mathrm{~d}$ & 18,86 & 15,76 bcd & 9,82 abcd & $12,13 \mathrm{a}$ & $44 \mathrm{a}$ & $19,83 \mathrm{abcd}$ & $0,74 \mathrm{a}$ & $26,83 \mathrm{ab}$ \\
\hline $\mathrm{A}+\mathrm{CS} 0,2 \%$ & $314,15 \mathrm{ab}$ & 2,83 & 19,16 & 15,90 bcd & $11,77 \mathrm{abcd}$ & $13,38 \mathrm{a}$ & $44 \mathrm{a}$ & 19,76 abcd & $0,74 \mathrm{a}$ & $26,86 \mathrm{ab}$ \\
\hline $\mathrm{A}+\mathrm{AG} 3$ & $418,75 \mathrm{a}$ & $4,18 \mathrm{~b}$ & $25,03 \mathrm{bc}$ & $16,90 \mathrm{abc}$ & $19,37 \mathrm{a}$ & $16,82 \mathrm{a}$ & $43 \mathrm{a}$ & 19,13 bcd & $0,79 \mathrm{a}$ & $24,13 \mathrm{ab}$ \\
\hline $\mathrm{AG} 3+\mathrm{CS} 0,1 \%$ & $401,58 \mathrm{ab}$ & $4,02 \mathrm{bc}$ & $24,66 \mathrm{bc}$ & $16,46 \mathrm{abcd}$ & $17,61 \mathrm{abc}$ & $14,63 \mathrm{a}$ & $37 \mathrm{a}$ & 18,66 & 0,79 a & $23,50 \mathrm{ab}$ \\
\hline $\mathrm{AG} 3+\mathrm{CS} 0,2 \%$ & $320,99 \mathrm{ab}$ & $4,19 \mathrm{~b}$ & $24,76 \mathrm{bc}$ & $16,83 \mathrm{abc}$ & $14,95 \mathrm{abcd}$ & $12,42 \mathrm{a}$ & $36 \mathrm{a}$ & $19,23 \mathrm{bcd}$ & $0,72 \mathrm{a}$ & $26,46 \mathrm{ab}$ \\
\hline $\mathrm{A}+\mathrm{AG} 3+\mathrm{CS} 0,1 \%$ & $412,46 \mathrm{a}$ & $4,74 \mathrm{ab}$ & $26,76 \mathrm{ab}$ & $17,13 \mathrm{a}$ & $19,13 \mathrm{ab}$ & $14,40 \mathrm{a}$ & $35 \mathrm{a}$ & $18,73 \mathrm{~cd}$ & $0,82 \mathrm{a}$ & $23,00 \mathrm{ab}$ \\
\hline $\mathrm{A}+\mathrm{AG} 3+\mathrm{CS} 0,2 \%$ & $426,13 \mathrm{a}$ & $5,30 \mathrm{a}$ & $27,53 \mathrm{a}$ & $18,03 \mathrm{a}$ & $19,36 \mathrm{a}$ & $15,50 \mathrm{a}$ & $24 \mathrm{a}$ & $18,76 \mathrm{~cd}$ & $0,83 \mathrm{a}$ & $22,70 \mathrm{~b}$ \\
\hline Média & 313,64 & 3,40 & 21,86 & 16,01 & 13,19 & 11,31 & 41,44 & 19,64 & $\mathbf{0 , 7 7}$ & 25,55 \\
\hline C. V. $(\%)$ & 22,55 & 8,27 & 3,83 & 3,56 & 25,24 & 35,96 & 26,45 & 2,60 & 6,94 & 7,80 \\
\hline
\end{tabular}

Médias seguidas pela mesma letra na coluna não diferem entre si, pelo teste Tukey, a 5\% de probabilidade.

\section{MATERIAL E MÉTODOS}

O experimento foi conduzido durante dois ciclos de produção nos anos de 2001 e 2002, em vinhedo da variedade Thompson Seedless, situado no Campo Experimental de Bebedouro, pertencente à Embrapa Semi-Árido, em Petrolina-PE (latitude 909' sul, longitude $40^{\circ} 22^{\prime}$ 'oeste e altitude média de $365 \mathrm{~m}$ ). O clima da região pode ser classificado, segundo Köepen, como tipo Bswh, que corresponde a uma região semiárida muito quente. $\mathrm{O}$ índice pluviométrico anual é de $571,5 \mathrm{~mm}$. A temperatura média anual é de $26,4^{\circ} \mathrm{C}$, com média das mínimas de $20,6^{\circ} \mathrm{C}$, e média das máximas $31,7^{\circ} \mathrm{C}$.

O sistema de condução utilizado foi a latada, com espaçamento 4 x $2 \mathrm{~m}$ e irrigação por microaspersão. As plantas foram enxertadas sobre o porta-enxerto IAC 572 'Jales' e tinham aproximadamente 4 anos de idade. Foram realizadas podas com varas (10 gemas) e esporões (2 gemas). Os demais tratos culturais foram aqueles recomendados para o sistema de produção de uvas de mesa no Vale do São Francisco (Leão \& Possídio, 2000)

O delineamento utilizado foi o de blocos casualizados, com três repetições e duas plantas úteis por parcela. Os tratamentos foram os seguintes: 1) Testemunha: sem aplicação de ácido giberélico, Crop Set e anelamento; 2) Anelamento (A); 3) Ácido giberélico $\left(\mathrm{AG}_{3}\right)$; 4) Crop Set (CS) 0,1\%; 5) Crop Set (CS) 0,2\%; 6) Anelamento + Crop Set $0,1 \%$; 7) Anelamento + Crop Set $0,2 \% ; 8)$ Anelamento + Ácido giberélico; 9) Ácido giberélico + Crop Set $0,1 \%$; 10) Ácido giberélico + Crop Set $0,2 \% ; 11)$ Anelamento + Ácido giberélico + Crop Set $0,1 \%$, e 12) Anelamento + Ácido giberélico + Crop Set $0,2 \%$.

$\mathrm{O}$ anelamento foi realizado quando as bagas apresentavam entre 8 a $9 \mathrm{~mm}$ de diâmetro, através de corte de cerca de 4 a $5 \mathrm{~mm}$ de largura no caule, a uma altura de cerca de $1,0 \mathrm{~m}$ do solo, utilizando-se de incisor com faca dupla. $\mathrm{O}$ ácido giberélico foi aplicado em cinco fases: $10 \mathrm{mg} . \mathrm{L}^{-1}$ quando os cachos tinham cerca de $2 \mathrm{~cm}$ de comprimento; 15 mg.L $\mathrm{L}^{-1}$ no início da floração; $15 \mathrm{mg} . \mathrm{L}^{-1} \mathrm{em}$ plena floração; $50 \mathrm{mg} . \mathrm{L}^{-1}$ após o pegamento dos frutos ou fase de 'chumbinho', e 50 mg.L $\mathrm{L}^{-1}, 7$ dias após a aplicação anterior. A pulverização foi dirigida aos cachos. O bioestimulante Crop Set foi aplicado junto com a última aplicação do ácido giberélico para crescimento de baga ( 8 a $9 \mathrm{~mm}$ de diâmetro de bagas).

Foram avaliadas as seguintes variáveis: produção (t/ha), número de cachos por planta, peso médio de cachos $(\mathrm{g})$; peso $(\mathrm{g})$, comprimento $(\mathrm{mm})$ e diâmetro médio de bagas $(\mathrm{mm})$; peso médio do engaço $(\mathrm{g})$; sólidos solúveis totais-SST ( $\left.{ }^{\circ} \mathrm{Brix}\right)$; acidez total titulávelATT (\% de ácido tartárico), e relação SST/ATT.

A determinação dos teores de açúcares foi realizada por meio de leitura em refratômetro digital, e a acidez total titulável por titulação com $\mathrm{NaOH} 0,1 \mathrm{~N}$.

A análise estatística dos dados obtidos consistiu na análise de variância e na comparação entre médias, pelo teste de Tukey ( $\mathrm{p}<$ 0,05), utilizando-se do programa SAS (1989).

\section{RESULTADOS E DISCUSSÃO}

No ciclo de produção de 2001, os tratamentos combinados de anelamento e ácido giberélico e anelamento, ácido giberélico e Crop Set $(0,1$ e $0,2 \%)$ promoveram cachos com maior peso médio, com diferenças significativas em relação à testemunha, observando-se um aumento de $114,6 \%$ no peso dos cachos tratados com anelamento + ácido giberélico + Crop Set $0,2 \%$ em relação à testemunha (Tabela 1). No ciclo de 2002, os maiores incrementos observados para peso de cachos foram de $172,4 \%$ no tratamento anelamento + ácido giberélico + Crop Set $0,1 \%$, comparado aos cachos tratados apenas com Crop Set $0,1 \%$ e de $157,1 \%$ quando comparado à testemunha (Tabela 2).

O ácido giberélico combinado com anelamento e Crop Set 0,2\% e ácido giberélico + anelamento + Crop Set 0,1\%, em 2002, destacaramse como os melhores tratamentos, respectivamente em 2001 e 2002, promovendo aumento no peso e tamanho das bagas, com diferenças significativas para a testemunha, anelamento, Crop Set e ácido giberélico aplicados isoladamente. Observou-se incremento no peso das bagas de $183,4 \%$ quando se utilizou do tratamento anelamento, ácido giberélico e Crop Set 0,2\%, em 2001, e de 79\% no tratamento anelamento, ácido giberélico e Crop Set 0,1\%, em 2002, em relação à testemunha. Em 2001, foi obtido um aumento de, respectivamente, 39 e $23 \%$ no comprimento e diâmetro das bagas nos cachos tratados com anelamento + ácido giberélico + Crop Set 0,2\% (Tabela 1). Em 2002, o comprimento de bagas obtido no tratamento anelamento + ácido giberélico + Crop Set $0,2 \%$ foi $29,4 \%$ superior àquele obtido na Testemunha, enquanto, para o diâmetro de bagas, o maior incremento observado neste ciclo foi de $12,3 \%$ no tratamento anelamento + ácido giberélico + Crop Set $0,1 \%$ em relação à Testemunha (Tabela 2). Observou-se, portanto, que o ácido giberélico foi mais eficiente para aumentar o comprimento do que o diâmetro da baga, pois, segundo Saad et al. (1979), o formato alongado das bagas é uma conseqüência das aplicações de ácido giberélico.

Os resultados obtidos para aumento do peso e tamanho de cachos e bagas estão de acordo com diversos autores que também observaram que os melhores resultados foram obtidos quando o ácido giberélico foi combinado ao anelamento (Saad et al., 1979; Ezzahouani et al., 1985; Harrel \& Williams, 1987). Observou-se uma ação sinérgica entre o Crop Set e o ácido giberélico, potencializando os efeitos sobre o aumento do tamanho das bagas, embora, quando aplicado isoladamente, este bioestimulante não tenha sido eficiente, o que está de acordo com diversos autores (Retamales et al., 1995; Ben Arie et al., 1997; Leão et al., 1999; Navarro et al., 2001), que trabalharam com o CPPU, citocinina sintética derivada da feniluréia.

Não foi observada influência significativa do anelamento sobre 
TABELA 2 - Efeitos do ácido giberélico (AG3), do anelamento (A) e do bioestimulante Crop Set (CS) sobre cachos e bagas da uva 'Thompson Seedless', 2002, Petrolina-PE.

\begin{tabular}{|c|c|c|c|c|c|c|c|c|c|c|}
\hline TRATAMENTOS & $\begin{array}{c}\text { Peso } \\
\text { de cachos (g) }\end{array}$ & $\begin{array}{c}\text { Peso } \\
\text { de bagas (g) }\end{array}$ & $\begin{array}{l}\text { Comprimento } \\
\text { de bagas }(\mathrm{mm})\end{array}$ & $\begin{array}{l}\text { Diâmetro de } \\
\text { bagas (mm) }\end{array}$ & $\begin{array}{c}\text { Peso do } \\
\text { engaço (g) }\end{array}$ & $\begin{array}{c}\text { Produção } \\
\text { (t/ha) }\end{array}$ & $\begin{array}{c}\text { Cachos/ } \\
\text { planta }\end{array}$ & $\begin{array}{c}\text { SST } \\
\left({ }^{\circ} \text { Brix }\right)\end{array}$ & $\begin{array}{l}\text { ATT } \\
(\%)\end{array}$ & $\begin{array}{c}\text { Relação } \\
\text { SST/ATT }\end{array}$ \\
\hline $\mathrm{T}$ & 118,85 c & $2,00 \mathrm{~cd}$ & $16,33 \quad \mathrm{~d}$ & $13,66 \mathrm{de}$ & $4,25 \quad c$ & $2,37 \mathrm{a}$ & $15 \mathrm{a}$ & $20,23 \mathrm{a}$ & 1,09 a & 18,59 a \\
\hline A & $223,83 \mathrm{abc}$ & $3,10 \mathrm{ab}$ & $19,68 \mathrm{bc}$ & $15,55 \mathrm{ab}$ & 8,82 abc & $4,14 \mathrm{a}$ & $23 \mathrm{a}$ & $19,26 \mathrm{a}$ & $1,16 \mathrm{a}$ & $16,63 \mathrm{a}$ \\
\hline AG3 & $159,50 \mathrm{bc}$ & $3,18 \mathrm{ab}$ & $21,69 \mathrm{ab}$ & $15,16 a b c$ & $12,00 \mathrm{a}$ & $4,73 \mathrm{a}$ & $22 \mathrm{a}$ & $19,10 \mathrm{a}$ & $1,08 \mathrm{a}$ & $17,69 \mathrm{a}$ \\
\hline CS $0,1 \%$ & $112,18 \quad \mathrm{c}$ & $2,00 \mathrm{~cd}$ & $15,98 \quad \mathrm{~d}$ & 13,44 & 4,06 & $2,28 \mathrm{a}$ & $15 \mathrm{a}$ & $19,26 \mathrm{a}$ & $1,02 \mathrm{a}$ & $18,75 \mathrm{a}$ \\
\hline $\mathrm{CS} 0,2 \%$ & 144,07 bc & $2,07 \mathrm{~cd}$ & 16,38 & 13,75 cde & 5,12 & $1,94 \mathrm{a}$ & $13 \mathrm{a}$ & $19,40 \mathrm{a}$ & $1,10 \mathrm{a}$ & 17,68 a \\
\hline $\mathrm{A}+\mathrm{CS} 0,1 \%$ & $171,65 \mathrm{abc}$ & $2,66 \mathrm{bc}$ & $17,94 \mathrm{~cd}$ & 14,74 abcde & 5,64 & 3,23 a & $22 \mathrm{a}$ & $19,76 \mathrm{a}$ & $1,09 \mathrm{a}$ & 18,11 a \\
\hline $\mathrm{A}+\mathrm{CS} 0,2 \%$ & $159,56 \mathrm{bc}$ & $2,16 \mathrm{~cd}$ & $16,94 \mathrm{~cd}$ & 14,30 bcde & 5,51 & 4,31 a & $24 \mathrm{a}$ & $19,36 \mathrm{a}$ & $1,14 \mathrm{a}$ & 17,19 a \\
\hline $\mathrm{A}+\mathrm{AG} 3$ & $207,48 \mathrm{abc}$ & $3,30 \mathrm{ab}$ & $22,26 \mathrm{ab}$ & $14,96 \mathrm{abcd}$ & $10,84 \mathrm{a}$ & $4,54 \mathrm{a}$ & $18 \mathrm{a}$ & $19,60 \mathrm{a}$ & $1,03 \mathrm{a}$ & $18,97 \mathrm{a}$ \\
\hline $\mathrm{AG} 3+\mathrm{CS} 0,1 \%$ & $236,36 \mathrm{abc}$ & $3,42 \mathrm{ab}$ & $22,49 \mathrm{ab}$ & $15,51 \mathrm{ab}$ & $10,61 \mathrm{a}$ & $5,07 \mathrm{a}$ & $23 \mathrm{a}$ & $18,60 \mathrm{a}$ & $1,08 \mathrm{a}$ & 17,28 a \\
\hline $\mathrm{AG} 3+\mathrm{CS} 0,2 \%$ & $213,99 \mathrm{abc}$ & $3,12 \mathrm{ab}$ & $21,78 \mathrm{ab}$ & $15,10 \mathrm{abc}$ & $9,66 \mathrm{ab}$ & $6,79 \mathrm{a}$ & $28 \mathrm{a}$ & $19,33 \mathrm{a}$ & $1,07 \mathrm{a}$ & $18,00 \mathrm{a}$ \\
\hline $\mathrm{A}+\mathrm{AG} 3+\mathrm{CS} 0,1 \%$ & $305,61 \mathrm{a}$ & $3,58 \mathrm{a}$ & $22,64 \mathrm{a}$ & $16,08 \mathrm{a}$ & $13,33 \mathrm{a}$ & 5,26 a & $18 \mathrm{a}$ & $19,26 \mathrm{a}$ & $1,09 \mathrm{a}$ & 17,69 a \\
\hline $\mathrm{A}+\mathrm{AG} 3+\mathrm{CS} 0,2 \%$ & $276,21 \mathrm{ab}$ & $1,37 \mathrm{~d}$ & $23,13 \mathrm{a}$ & $15,58 \mathrm{ab}$ & $12,56 \mathrm{a}$ & $6,35 \mathrm{a}$ & $22 \mathrm{a}$ & $17,73 \mathrm{a}$ & $1,21 \mathrm{a}$ & $14,64 \mathrm{a}$ \\
\hline Média & 194,10 & 2,66 & 19,77 & 14,82 & 8,53 & 4,25 & 20,55 & 19,24 & 1,10 & 17,60 \\
\hline C. V. $(\%)$ & 24,85 & 11,41 & 4,82 & 3,22 & 18,94 & 40,67 & 31,40 & 4,31 & 7,59 & 9,44 \\
\hline
\end{tabular}

Médias seguidas pela mesma letra na coluna não diferem entre si, pelo teste de Tukey, a 5\% de probabilidade

o tamanho das bagas, o que difere dos resultados obtidos por Harrel \& Williams (1987) nesta variedade.

O ácido giberélico promoveu aumento no peso do engaço, sendo que, nos dois ciclos, os engaços com maior peso foram observados nos tratamentos combinados de anelamento, ácido giberélico e Crop Set, bem como ácido giberélico isolado ou combinado com anelamento. Navarro et al. (2001) obtiveram resultados semelhantes trabalhando com CPPU combinado com o ácido giberélico. Este fato está relacionado ao aumento da atividade da peroxidase nos pedicelos das bagas tratadas com ácido giberélico (Perez \& Gomes, 1998).

Apesar de não serem observadas diferenças significativas entre os tratamentos, em 2001, houve um aumento de $150 \%$ na produção, quando os três tratamentos foram combinados em relação à Testemunha (Tabela 1). A ausência de significância para esta característica, apesar das diferenças observadas entre os tratamentos, pode ter sido conseqüência dos valores elevados do coeficiente de variação (Tabelas 1 e 2). O número de cachos por planta não foi padronizado e isto pode justificar a elevada variação na produção por planta entre os tratamentos. O maior peso de cachos nos tratamentos onde foram combinados o anelamento, ácido giberélico e Crop Set, justificam a produção mais elevada nestes tratamentos.

Em 2001, o ácido giberélico reduziu o teor de sólidos solúveis totais (SST), observando-se o menor teor de açúcares nos tratamentos onde ele estava presente, diferindo significativamente da testemunha. Não houve influência sobre a acidez total titulável (ATT). Por outro lado, a relação SST/ATT foi reduzida no tratamento anelamento + ácido giberélico + Crop Set $0,2 \%$ em relação à testemunha, em conseqüência dos menores valores de SST e maior ATT obtido naquele tratamento. Em 2002, não houve influência dos tratamentos sobre a composição química dos frutos. No entanto, observou-se teor elevado de acidez total em todos os tratamentos, cuja média foi de $1,10 \%$, o que provocou a redução da relação SST/ATT. A redução no teor de sólidos solúveis, nos tratamentos com ácido giberélico, no ciclo de 2001, está de acordo com Saad et al. (1979) e Harrel \& Williamns (1987), que justificam este fato devido à variação na produção, influenciada pelos tratamentos, enquanto outros autores, trabalhando com 'Thompson Seedless', não encontraram influência do ácido giberélico ou do anelamento sobre a composição química dos frutos (Weaver \& Pool, 1971; Ezzahouani et al., 1985). A composição química dos frutos, nos tratamentos Crop Set e Crop Set + Anelamento, não diferiu da testemunha nos dois ciclos de produção, discordando dos resultados obtidos por outros autores quando utilizaram o CPPU (Retamales et al., 1995; Ben Arie et al., 1997; Leão et al., 1999; Navarro et al., 2001).

De maneira geral, o ciclo de produção de 2001 favoreceu a obtenção de resultados superiores para todas as características avaliadas, o que pode ser justificado pelo fato de a safra colhida em 2001 ter sido realizada após dois ciclos de formação das plantas, quando houve, portanto, um armazenamento de reservas, fato este que não foi observado em 2002. Além disso, alternância entre safras é observado comumente em variedades de uvas sem sementes no Vale do São Francisco.

O anelamento apresentou problemas para a cicatrização normal do câmbio, possivelmente pela idade e diâmetro do caule das plantas. Este fato levou à morte muitas plantas. Cirami et al. (1992) mencionam, ainda, que o anelamento realizado sucessivamente após vários anos poderá reduzir o tamanho dos cachos e a vida útil das plantas. Evidenciase, portanto, o alto risco desta prática, devendo ser realizada com cautela, dando-se preferência, nas condições do Vale do São Francisco, ao emprego combinado de ácido giberélico e do bioestimulante Crop Set.

\section{CONCLUSÕES}

1. O ácido giberélico associado ao anelamento no caule e ao bioestimulante Crop Set promoveu aumento no peso e tamanho dos cachos e das bagas na variedade Thompson Seedless.

2. Os engaços dos cachos tratados com ácido giberélico apresentaram maior peso, o que não prejudicou a formação e a aparência dos cachos.

3. O teor de sólidos solúveis totais foi reduzido pela aplicação do ácido giberélico.

4. O tratamento ácido giberélico + bioestimulante Crop Set $0,1 \%$ pode ser recomendado para aumentar o peso e o tamanho de cachos e bagas da uva 'Thompson Seedless' no Vale do São Francisco.

\section{REFERÊNCIAS}

BEN ARIE, R.; SARIG, P.; COHEN AHDUR, Y., SONEGO, L., KAPULONOV, T.; LISKER, N. CPPU and $\mathrm{GA}_{3}$ effects on pre- and post-harvest quality of seedless and seeded grapes. Acta Horticulturae, Wageningen, n.463, p.349-357, 1997.

CIRAMI, R. M.; CAMERON, I. J.; HEDBERG, P. R. Special Cultural Methods for tablegrapes. In: COOMBE, B.G.; DRY, P.R. Viticulture. Adelaide: Ed. Winetitles, 1992. v.2, p.279-301.

EZZAHOUANI, A.; LASHEEN, A. M.; WALALI, L. Effects of gibberellic acid and girdling on 'Thompson Seedless' and 'Ruby Seedless' table grapes in Morocco. HortScience, Alexandria, v.20, n.3, 1985.

HARREL, D.C.; WILLIAMS, L.E. The influence os girdling and gibberellic acid application at fruit set on Ruby Seedless and Thompson Seedless grapes. American Journal of Enology and Viticulture, Davis, v.38, n.2, 1987.

LEÃO, P.C. de S.; LINO JUNIOR, E.C.; SANTOS, E. S. Efeitos do CPPU e ácido giberélico sobre o tamanho de bagas da uva Perlette cultivada no Vale do São Francisco. Revista Brasileira de Fruticultura, Cruz 
das Almas, v.21, n.1, p.74-78, 1999.

LEÃO, P. C. de S.; POSSÍDIO, E. L. de. Implantação do pomar e manejo da cultura. In: LEÃO, PC. de, SOARES, J.M. (Ed.) A Viticultura no semi-árido brasileiro. Petrolina: Embrapa Semi-Árido, 2000. 366p.

METIVER, J. R. Citocininas In: FERRI, M. G. (ed.). Fisiologia vegetal 2. São Paulo: EDUSP, 1979. p.93-127.

NAVARRO O., M.; RETAMALES A., J.; DEFILIPPI B., B. Efecto del arreglo de racimo y aplicación de citoquinina sintética (CPPU) en la calidad de uva de mesa variedad Sultanina tratada con dos fuentes de giberelinas. Agricultura Técnica, Santiago, v.61, n.1, p.15-25, 2001.

PEREZ, F. J.; GOMES, M. Gibberellic acid stimulation of isoperoxidase from pedicel of grape. Phytochesmistry, Oxford, v.48, n.3, p.411414, 1998.

PIRES, E. J. P. Emprego de reguladores de crescimento em viticultura tropical. Informe Agropecuário, Belo Horizonte, v.19, n.194, p.3439, 1998.

RETAMALES, J; BANGERTH, F.; COOPER, T.; CALLEJAS, R. Effects of CPPU and $\mathrm{GA}_{3}$ on fruit quality of Sultanina table grape. Acta Horticulturae, Wageningen, 394, p.149-157, 1995.
SAAD, F. A.; EL-HAMADY, A. A. M.; HAMOUDA, M. M. Effect of gibberellic acid and ethephon on berry weight, size and quality of Thompson Seedless and Delight grapes. Proceedings Saudi Biology Society, v.3, p.35-46, 1979.

SAS Institute. SAS/STAT User's guide. $4^{\text {th }}$ ed. Cary, NC, 1989. v.1, 943p.

TAIZ, L.; ZEIGER, E. Plant physiology. California: The Benjamin Cummings Publishing, 1991. 559p.

WEAVER, R. J.; POOL, R. M.; Berry response of 'Thompson Seedless' and 'Perlette' grapes to application of gibberellic acid. Journal of the American Society Horticultural Science, Alexandria, n.96, v.2, p.162-166, 1971.

WINKLER, J. A. General viticulture. Berkeley:University of California Press, 1974. 710p.

ZIOZIOU, E.; NIKOLAOU, N. A.; VRIZAS, Z. Applications de régulateurs de croissance sur la sultanine, pour la production de raisins de table. Progrès Agricole et Viticole, Montpellier, v.116, n.10, p.228-230, 1999. 